\title{
Studies of the Distribution of Ultraviolet Sky Radiation (VIII)
}

- On the Effect of the Ozone Absorption Layer -

by

\author{
K. Sekihara, K. Murai and M. Kano \\ Meteorological Research Institute \\ (Received January 16, 1958)
}

\begin{abstract}
Using a photomultiplier tube and filters, the intensities of ultraviolet sky radiation from various directions were measured at Mt. Norikura in summer 1957. The measurement was done in two different wave-length ranges, i.e. $3200 \AA$ and $3300 \AA$ or so respectively, with the aim of finding the effect of the ozone layer in the upper atmosphere. The measurement of the intensities of U. V. sky radiation was done in three directions in the principal meridian plane, that is, in the zenith distance of $15^{\circ}$ towards the sun, just in the zenith and in that of $15^{\circ}$ backward of the sun. Also each measurement was carried out at every four or five minutes during the time when the sun's altitude was from $0^{\circ}$ to $30^{\circ}$. The relative values were computed at each instant taking the values in the zenith as a unit. Then their time variation was examined especially in view of its difference between the two wave lengths. Investigating the results of observation a rapid increase of the difference was pointed out when the sun's altitude was lower than two or three degrees.

These phenomena were theoretically analyzed, computing the primary scattered intensities in the atmosphere with a typical absorption layer and also without it. And the above-mentioned feature was proved to be the effect of an ozone absorption layer. Thus a new method of determining the vertical distribution of the atmospheric ozone was suggested.
\end{abstract}

\section{Introduction}

The atmospheric ozone has been studied since the end of last century. Since FABRY and BUISSON (1921) established that the atmospheric ozone played a great role in the absorption of ultraviolet solar radiation, studies on this problem have been carried out by many investigators as problems on the ozonosphere, and thereafter the total amount and the vertical distribution of the atmospheric ozone gradually have been made clear (Götz, Meetham, and Dobson, 1934). Meanwhile, the mechanism of the production of ozonosphere has been solved by the use of the available knowledge of photo-chemistry (CRAIG, 1950, DüTsch, 1956). Recently, the 
heating caused by the absorption of solar radiation and the cooling caused by the infra-red outgoing radiation at the ozonosphere have excited an interest in relation to the dynamics in the upper atmosphere (Tech, Rep. High Altitude Observatory, 1956), and in consequence the right pictures of the vertical distribution of the atmospheric ozone are now seriously required.

The total amount of atmospheric ozone in a vertical column of the atmosphere has long been measured, while about its vertical distribution our knowledge is still insufficient. The information about it is obtained indirectly by the use of GöTz's effect from the measurement of the ultraviolet sky radiations at the ground (GöTz, Meetham and Dobson, 1934) and directly by the use of rocket measurement (Johnson, Purcell, Tousey and Watanabe, 1952) or that of the balloon using the absorption of the direct solar radiations (REGENER, E. and V.H., 1934). The direct method may be the best way, but little data are available by this method at present and this must be developed in furture. The accuracy of the indirect method is not very good (WALTON, 1957), but at present the indirect method at the ground surface is the most conveniently as it is the easiest one to handle and also the most economical.

Now, the method using Görz's effect is based on the measurement of the ultraviolet sky radiation from the zenith direction. In addition to this, as means of determining vertical distribution of atmospheric ozone, there are others proposed, that is, measurement of direct solar radiation (Гущин, 1957) in the ultraviolet region and measurement of the absorption of solar radiation in the infra-red region (EPSTEIN, Osterberg and Adel, 1956). But these two methods are not yet sufficiently developd, so that they are used at only a few stations in the world. In short, among the methods of surface measurement the one using Götz's effect is the most widely used. But unfortunately the poor accuracy of this method has already often been pointed out, and so some attempts to improve this situation are very desirable.

With respect to this method, CHApman (1935) early suggested the use of the ultraviolet radiation in directions besides the zenith direction when he computed the problem of Görz's effect, and recently WALTON (1957) has also expressed a similar suggestion.

We have been interested in the angular distribution of the ultra-violet sky radiation for a long time and have published several reports in this connection (SEKIHARA, 1950). Furthermore we are going to study the aspects of the atmospheric ozone on the basis of measurement and calculation of the distribution of the ultraviolet sky radiation.

\section{Apparatus}

The measuring apparatus consists of a photomultiplier with various filters and it is set on the theodolite. It is used to measure the sky radiations in two different spectrum regions which are strongly or weakly absorbed by the atmospheric ozone respectively. The picture of the apparatus and the schema of its inner structure are given in Figs. 1 and 2. As shown in these figures, the sky radiation enter into the apparatus through the diaphragm filter, quartz lens, diaphragm reflection mirror and the photo-multiplier tube; in this order. The aperture into which sky radiation enters is about two degrees. Of the two kinds of filters one is made of quartz 

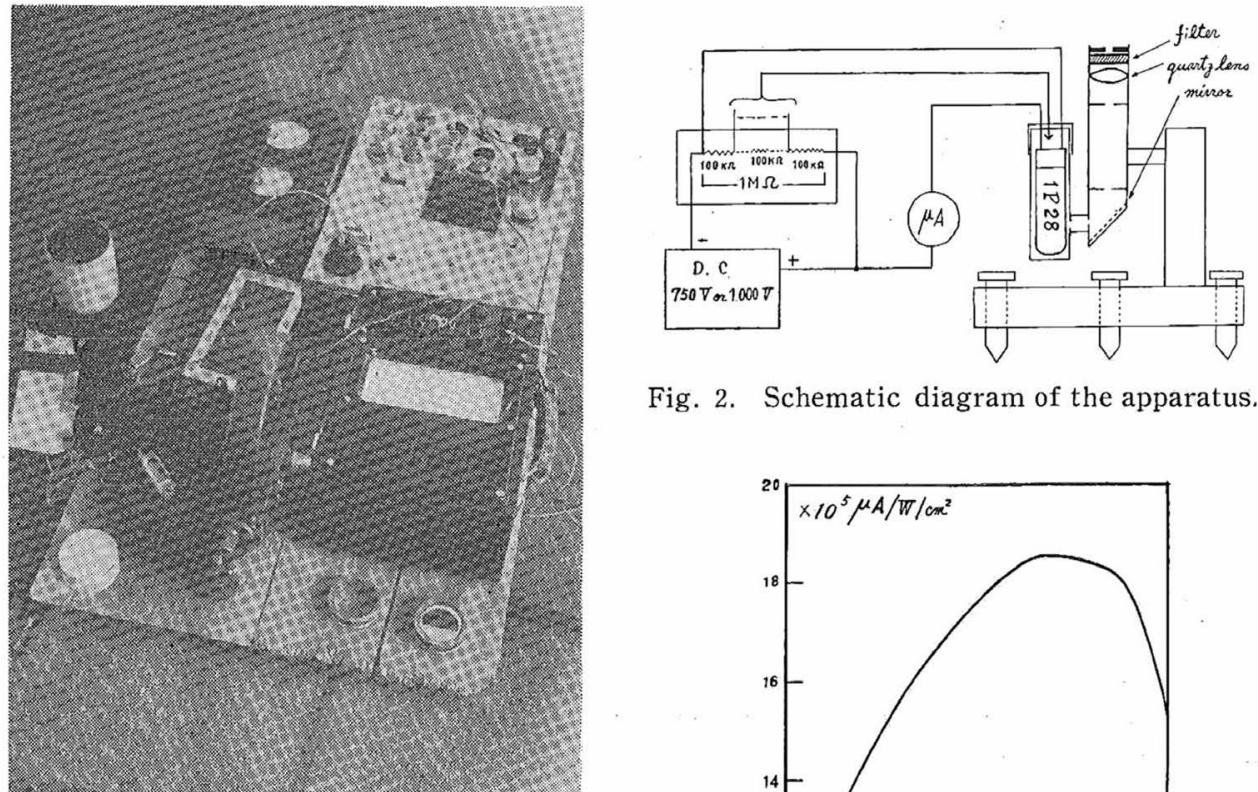

Fig. 2. Schematic diagram of the apparatus.

Fig. 1. Photograph of measuring apparatus of U.V. sky radiation.
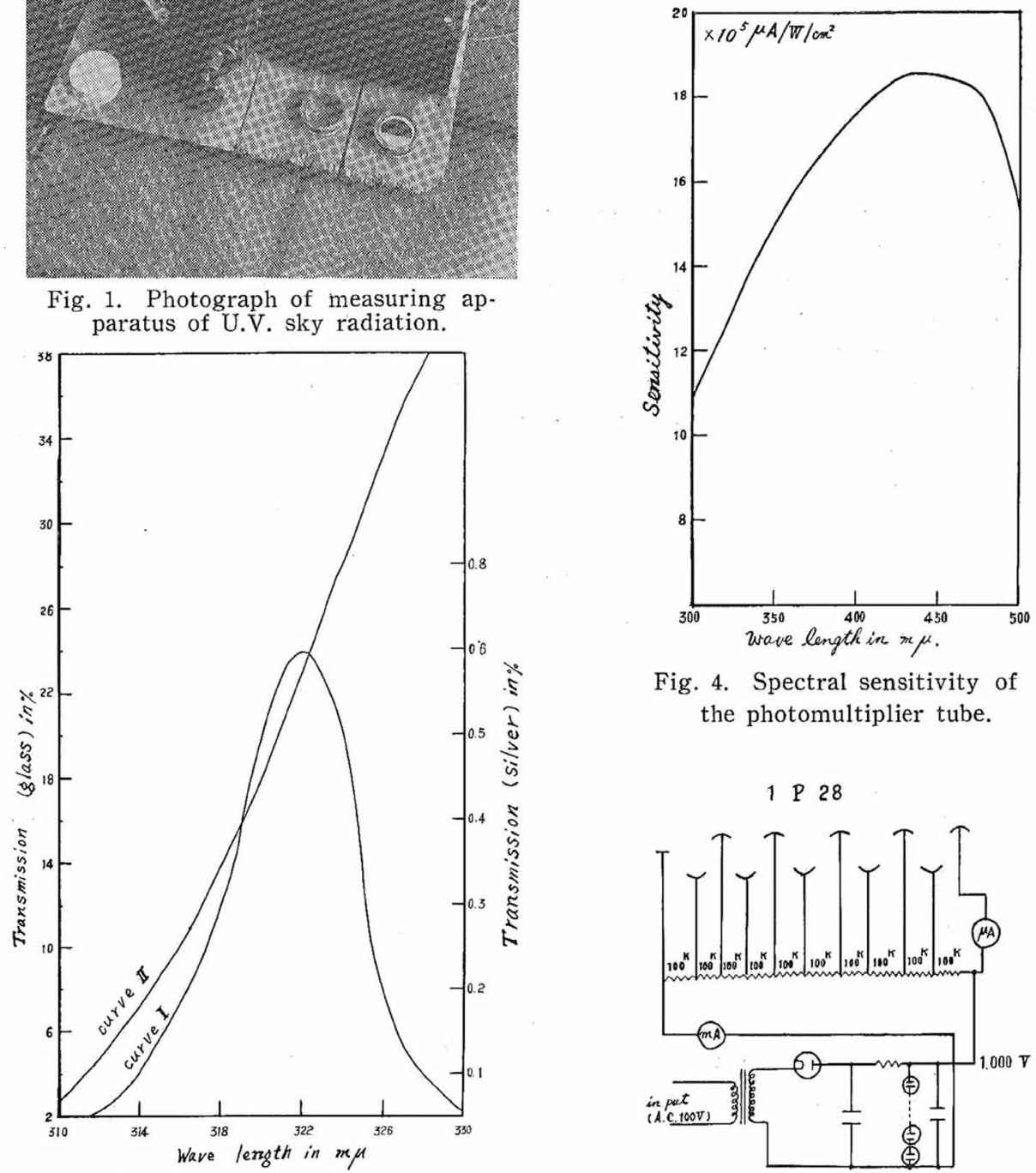

Fig. 4. Spectral sensitivity of the photomultiplier tube.

$1 \quad P 28$

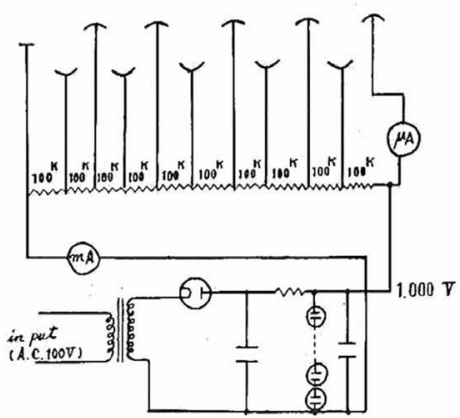

Fig. 5. Diagram of electrical connexions of the apparatus. a silver spattered quartz glass and curve II, to a window glass. 
glasses silvered by evaporation spattering which is used to introduce the ultraviolet radiation of neccessary wave length and another is a window glass to separate the $U$. V. radiation into a longer and shorter region. The transmission of these filters are shown in Fig. 3. The spectral sensitivity of the multiplier is given in Fig. 4. As shown in Figs. 3 and 4, the spectrum region near $3,300 \AA$ is measured by the appratus with two filters and the spectrum region near $3,200 \AA$ is measured without the window glass filter. The directions of the incoming radiation are determined within an error less than $\pm 1^{\circ}$ and this accuracy is sufficient for our observations.

The supply voltage was maintained in 1,000 volts or 750 volts according as the incoming radiation was weak or strong. The supply voltage is devided and applied to each electrode of the photomultiplier. The electrical diagram is shown in Fig. 5. The resulting currents caused by the incident light are read with the microammeter at each observation.

\section{Method of observation}

As described above, measurement was done in two spectrum regions, whose wave-lengths do not differ from each other so much but where the absorptive powers of ozone differ considerably. Also measurement was done in three directions in the meridian plane, that is, the direction of $15^{\circ}$ from the zenith towards the sun (we denote this by $+15^{\circ}$ below), the direction of the zenith itself and the direction of $15^{\circ}$ from the zenith away from the sun (we denote this by $-15^{\circ}$ below) respectively. Measurement of different spectral ranges was done both with and without the glass filter, as mentioned above. The observations were made at an interval of a few or ten minutes, and each observation took about one minute.

\section{Results obtained}

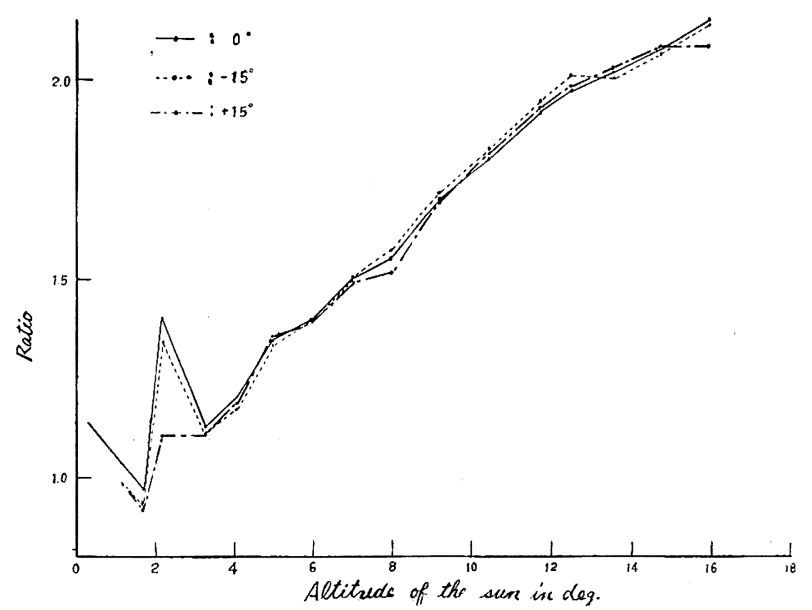

Fig. 6. Curves of the Görz's effect which are observed at Mt. Norikura in the direction $+15^{\circ}$ (toward the sun), $0^{\circ}$ and $-15^{\circ}$ (opposite the sun) respectively. Ordinate shows the ratio of the observed intensity of U.V. sky radiations each with or without the filter of a window glass. Abscissa shows sun's altitude in degrees.
The observations were done on clear days in the periods when the sun's altitude was comparatively low, and the accuracy of measurements, especially when the sun's altitude was less than three degrees, was rather poor. The observed data were scattered widely when the sun's altitude was lower than three degrees. This seems to be mainly due to the fact that the observations were not done simultaneous$1 y$, and also the dust and smog in the atmosphere might be the origin of the dispersions of observed data.

First we shall examine 
GöTz's effect. The ratios of the intensities in two spectrum regions of the ultraviolet sky radiation at various sun's altitudes are shown in Fig. 6, in which the three curves are based on the measurement at $+15^{\circ}, 0^{\circ}$ (zenith) and $-15^{\circ}$ respectively. These data are based on the measurements at Mt. Norikura $(2,840 \mathrm{~m}$ above sea level) and may be comparatively free from the effects of the atmospheric dust and smog. The figure shows that the curves have the minimum values near about two degrees of the sun's altitude, although the data are fairly scattered there. These differences among the three curves are not remarkable. Similar curves were obtained on the measurements at Tokyo, but these data proved to be scattered more conspicuously and we shall not show them here. Now this kind of data can be obtained with higher accuracy by DoBson's spectrometers which are widely used. So we satisfy ourselves with the fact that our data agree with the experience obtained until now.

And now we shall consider the relation between the angular distribution of the ultraviolet sky radiation and the effect of ozone absorption. Now relative intensities are computed from observed values at each instant, taking each value of the zenith as a unit. Then the time variation of the difference between the two wave lengths is discussed as follows. Indicating each spectrum region by the suffixes 1 and 2, and the zenith distance of the incoming radiation by the figures in the brackets, the ratios $(r)$ of the intensities in the direction of $+15^{\circ}$ and that in the direction of $0^{\circ}$ at each spectrum region can be given by

$$
r_{1}=I_{1}\left(15^{\circ}\right) / I_{1}\left(0^{\circ}\right) \text { and } r_{2}=I_{2}\left(15^{\circ}\right) / I_{2}\left(0^{\circ}\right) \text {, }
$$

respectively. Now we shall consider the variations of $\left(r_{1}-r_{2}\right)$ with the sun's altitude. The values are based on the data obtained at Mt. Norikura as shown in Fig. 7. The

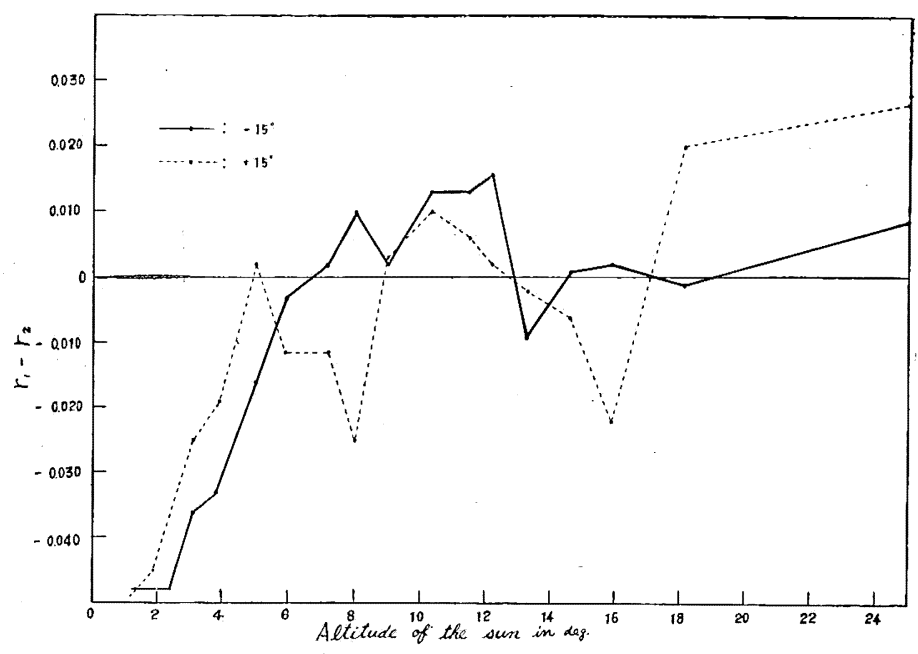

Fig. 7. Variation of the difference of the distribution of U.V. sky radiation. Ordinate shows $r_{1}-r_{2}$ where $r_{1}=I_{1}\left(15^{\circ}\right) /$ $I_{1}\left(0^{\circ}\right)$ and $r_{2}=I_{2}\left(15^{\circ}\right) / I_{2}\left(0^{\circ}\right): I_{1}\left(15^{\circ}\right)$ denoting the intensity from $15^{\circ}$ of zenith distance in the shorter wave-length region $(3,200 \stackrel{\circ}{\mathrm{A}}$ or so) and so on. The abscissa shows sun's altitude in degrees. Also it is based on the measurement at Mt. Norikura. 
two curves refer to the values in the direction of $\left(+15^{\circ}\right)$ and in the direction of $\left(-15^{\circ}\right)$ respectively.

The characteristic feature of these curves is the rapid increase during the time when sun's altitude is lower than two or three degrees whereas when the sun's altitude is more than this, the curves are rather flat. Because this period corresponds just to the time near the minimum of the umkehr curve, it is reasonable to attribute this characteristic to the influence of the ozone absorption layer. This feature and others will be discussed in detail in the next section, where the absorption layer in the upper atmosphere will be shown to play an important role.

The fluctuations of the observed values which can be pointed out near the low altitude of the sun may be regarded as an observational error caused by the rapid changes of the intensities at that time. In order to improve the accuracy of measurents and make it possible to compare them with theoretical calculations, it is necessary to design a new instrument by which simultaneous measurement of the radiations in different directions is possible.

\section{Numerical analysis and discussions}

As shown above, we obtained a characteristic feature of the curves which might represent the effect of the absorption by the atmospheric ozone, but in order to make it sure we shall make some numerical calculations. We shall compute the primary scattered light in the spectral regions similar to that of measurement, in cases with and without an absorption layer. We assume a uniform, plane stratified absorption layer of a finite thickness in the atmosphere. The scheme of calculation follows that in the paper III of one of the present author (SEKIHARA, 1950).

Denoting the optical height by $m$ which is defined by the expression $m=\int_{0}^{z} \rho d h / M$, where $\rho$ is the air density at a given height in the atmosphere, $h$ is the altitude. Also $M$ is the total mass of the atmospheric column with the base of $\mathrm{cm}^{2}$ and is defined by the expression $M=\int_{0}^{\infty} \rho d h$. Thus the optical depth $\bar{m}$, is given by $(1-m)$.

We denote the optical height of upper and lower boundaries of the absorption layer by $\mu_{1}$ and $\mu_{2}\left(\mu_{1}>\mu_{2}\right)$ respectively and also the absorption coefficient of the absorption layer (per unit optical depth) by $a$. Now, for the intensity of the scattered radiation received at the ground, we consider separately the contribution from the absorption layer and that from the layers above and below the absorption layer. Denoting the extinction coefficient of the latter layers by $s+a$ and that of the former layer by $s$, then the emission in each layer is given by

$$
\begin{array}{cc}
E_{1}(s, z, \theta, \varphi, m)=\frac{3 \sigma}{16 \pi} I_{\infty}\left(1+\cos ^{2} \psi\right) e^{-s \bar{m} \sec z} & 1>m>\mu_{1} \\
E_{2}\left(s, a, \mu_{1}, z, \theta, \varphi, m\right)=\frac{3 \sigma}{16 \pi} I_{\infty}\left(1+\cos ^{2} \psi\right) e^{-s \bar{\mu}_{1} \sec z} e^{-(a+s)\left(\bar{m}-\bar{\mu}_{1}\right) \sec z} \\
E_{3}\left(s, a, \mu_{1}, \mu_{2}, z, \theta, \varphi, m\right) \\
=\frac{3 \sigma}{16 \pi} I_{\infty}\left(1+\cos ^{2} \phi\right) e^{-\left\{s \bar{\mu}_{1}+(a+s)\left(\bar{\mu}_{2}-\bar{\mu}_{1}\right)+s\left(\bar{m}-\bar{\mu}_{2}\right)\right\} \sec z} \\
\mu_{2}>m>0
\end{array}
$$


where

$I_{\infty}$ : the intensity of the extraterrestrial direct solar radiation per unit cross section normal to the sun and per minute,

$\sigma$ : the scattering coefficient per unit mass in the atmosphere,

$s$ : the total scattering coefficient of the atmospheric column with the base of a unit area $(=M \sigma)$,

$z:$ the sun's zenith distance,

$\phi$ : the angle between the direction of the incident light and that of the scattered light, and is given by the expression, $\cos \phi=\cos z \cos \theta+\sin z \sin \theta \cos \varphi$.

$0:$ the zeinth distance of the incoming light,

$\varphi$ : the azimuthal angle of the incoming light measured from the sun's vertical plane.

The other notations are the same as were used previously.

The intensity of the primary scattered skylight received at the ground is given by the sum of the contributions from each layer, that is, $R_{d}=R_{d 1}+R_{d 2}+R_{d 3} . R_{d_{i}}$ $(i=1,2,3)$ are given by the following integrations:

$$
\begin{aligned}
& R_{d 1}=\int_{\mu_{1}}^{1} e^{-\left\{s\left(m-\mu_{1}\right)+(a+s)\left(\mu_{1}-\mu_{2}\right)+s \mu_{2}\right\} \sec \theta} E_{1}(m) M \sec \theta d m, \\
& R_{d 2}=\int_{\mu_{2}}^{\mu_{1}} e^{-\left\{s \mu_{2}+(a+s)\left(m-\mu_{2}\right)\right\} \sec \theta} E_{2}(m) M \sec \theta d m, \\
& R_{d 3}=\int_{0}^{\mu_{2}} e^{-\operatorname{sm} \sec \theta} E_{3}(m) M \sec \theta d m .
\end{aligned}
$$

Substituting the expressions ( $1 \mathrm{a}),(1 \mathrm{~b})$ and $(1 \mathrm{c})$ into the above expressions and integrating them,

$$
\begin{aligned}
& R_{d 1}=\frac{3 s}{16 \pi} I_{\infty}\left(1+\cos ^{2} \psi\right) \sec \theta \cdot e^{-s \sec \theta} \cdot e^{-a\left(\mu_{1}-\mu_{2}\right) \sec \theta} \frac{e^{s \mu_{1}(\sec \theta-\sec z)}-1}{s(\sec \theta-\sec z)}, \\
& R_{d 2}=\frac{3 s}{16 \pi} I_{\infty}\left(1+\cos ^{2} \psi\right) \sec \theta \cdot e^{-s \sec \theta} \cdot e^{-a\left(\bar{\mu}_{2} \sec \theta-\bar{\mu}_{1} \sec z\right)} \\
& \times \frac{e^{(a+s) \bar{\mu}_{2}(\sec \theta-\sec z)-e(a+s) \bar{\mu}_{1}(\sec \theta-\sec z)}}{(a+s)(\sec \theta-\sec z)}, \\
& R_{d 3}=\frac{3 z}{16 \pi} I_{\infty}\left(1-\cos ^{2} \phi\right) \sec \theta \cdot e^{-s \sec \theta} e^{-a\left(\bar{\mu}_{2}-\bar{\mu}_{1}\right) \sec z} \\
& \times \frac{e^{s(\sec \theta-\sec z)}-e^{s \bar{\mu}_{2}(\sec \theta-\sec z)}}{s(\sec \theta-\sec z)} .
\end{aligned}
$$

Then $R_{d}$ is given by

$$
\begin{aligned}
& R_{d}\left(s, a, \mu_{1}, \mu_{2}, z, \theta, \varphi\right) \\
& =\frac{3 s}{16 \pi} I_{\infty}\left(1+\cos ^{2} \phi\right) \sec \theta \cdot e^{-s \sec \theta}\left[e^{-a\left(\bar{\mu}_{2}-\bar{\mu}_{1}\right) \sec \theta} \cdot \frac{e^{s \bar{\mu}_{1}(\sec \theta-\sec z)}-1}{s(\sec \theta-\sec z)}\right. \\
& +e^{-a\left(\bar{\mu}_{2} \sec \theta-\bar{\mu}_{1} \sec z\right)} \frac{e^{(a+s) \bar{\mu}_{2}(\sec \theta-\sec z)}-e^{(a+s) \bar{\mu}_{1}(\sec \theta-\sec z)}}{(a+s)(\sec \theta-\sec z)} \\
& \left.+e^{-a\left(\bar{\mu}_{2}-\vec{\mu}_{1}\right) \sec z} \frac{e^{s(\sec \theta-\sec z)}-e^{s(\sec \theta-\sec z) \bar{\mu}_{2}}}{s(\sec \theta-\sec z)}\right] .
\end{aligned}
$$


We calculated $R_{d}$ in two different spectra in the directions of $+15^{\circ}, 0^{\circ}$ and $-15^{\circ}$ with the aid of. (3) and give the difference of $R_{d}\left(+15^{\circ}\right) / R_{d}\left(0^{\circ}\right)$ in two different spectra as a function of the sun's zenith distance.

Next, we calculate the difference of $R\left( \pm 15^{\circ}\right) / R\left(0^{\circ}\right)$ with respect to the case without the absorption layer as it was done in the case with the absorption layer. In this case, we get the simple expression as follows:

$$
\begin{aligned}
R_{d} & =\int_{0}^{1} e^{-s m \sec \theta} E(m) M \sec \theta d m \\
& =\frac{3 s}{16} I_{\infty}\left(1+\cos ^{2} \psi\right) \sec \theta \cdot e^{-s \sec z} \frac{e^{-s(\sec \theta-\sec z)}-1}{s(\sec \theta-\sec z)},
\end{aligned}
$$

Using this expression, we can calculate numerically the difference of $R_{d}\left( \pm 15^{\circ}\right) /$ $R_{d}(0)$ between different wavelengths as a function of the sun's altitude.

We show graphically calculated results in Fig. 8. This figure shows that the character of the curve in the case with the absorption layer is clearly distinguished from that in the case without the absorption layer. These results explain qualitatively the tendency of the observed curves in Fig. 7, that is, when the absorbing layer is assumed, the rapid increases in the curves appear near the low sun altitude, but it disappears in the case without the absorption layer, and the curves have a feature which shows a more gradual slope as a whole.

The two curves in Fig. 9 are those of the calculated ratios of the intensities

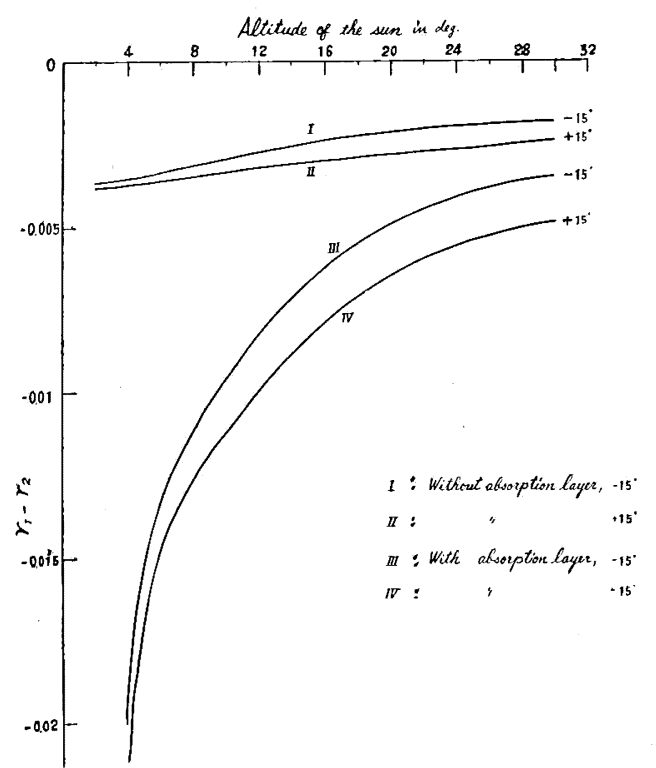

Fig. 8. Theoretical curves of $r_{1}-r_{2}$ both when an absorption layer is assumed to exist and when it is not assumed to exist. We can see the rapid variation of the curve only when there is an absorption layer.

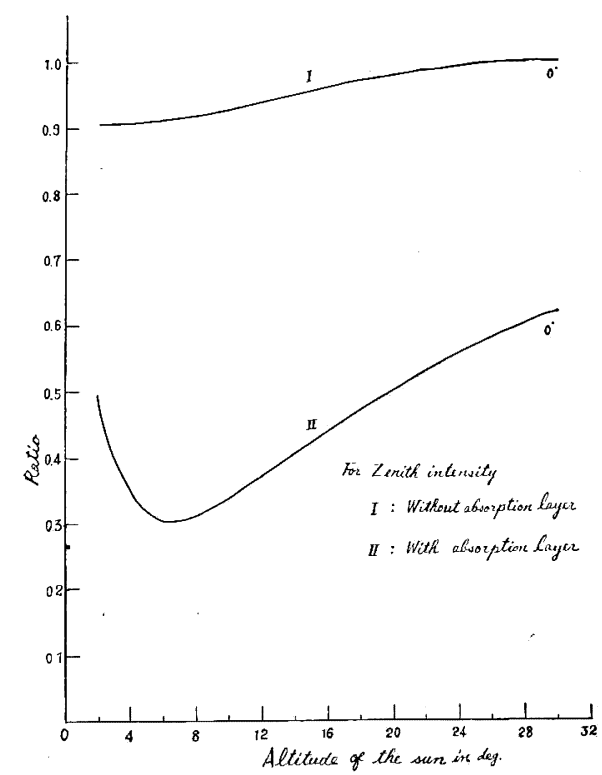

Fig. 9. Theoretical Umkehr curves both when an absorption layer is assumed to exits and when it is not assumed. Minimum occurs only in the former case. 
in the two idifferent wavelengths, and show that Götz's effect appears in the case with the absorption layer. These curves are drawn in order to ascertain the effect of the absorption layer. These curves can be regarded as evidence of the effect of the absorption layer in the upper atmosphere.

\section{Concluding remarks}

We observed the intensities of the ultraviolet sky radiation from various directions in order to obtain the amount and the vertical distribution of the atmospheric ozone quantitatively.

As described above, the data are scanty which can be compared with the theoretical computations, but the following may be said as conclusion of the present work. Considering the relative intensities of sky radiation in the direction of $15^{\circ}$ of zenith distance as compared with that of the zenith, the difference between the two wave lengths, i.e. those of strong and weak ozone absorption, increases rapidly with decreasing sun's altitude during the time when the sun's altitude is very low. This can be proved theoretically through the computation for the case the absorption layer but can not be found in the case without it. Therefore, this can be regarded as the effect of the ozone absorption layer, and moreover it should be pointed out that these effects appear during the time when GöTz's effect occurs.

In order to study these phenomena more in detail, we should design a new instrument by which we can measure the sky radiation in various directions simultaneously. Also we should theoretically take into account the effects of multiply scattered light and of non-RAYLEIGH scattering caused by the atmospheric smog and haze.

Acknowledgements-_-We are greatly indebted to the members of Cosmic Ray Observatory at Mt. Norikura who kindly offered us much convenience in our field work, to Dr. K. Yoshie, Chief of the Laboratory of Standard Light Source, and his collaborators for their kind advice and help in checking the instrument, to Dr. Hatakeyama, the Director of the Meteorological Research Institute, who read this manuscript and gave valuable advices, and to Miss Reıko Mukai for her earnest assistance in calculation and figure drawing. The authors express sincere gratitude to all of them.

\section{References}

Chapman, S., 1935: The Gör'm Inversion of intensity ratio in zenith-scattered sunlight, phil. Trans. of Roy. Soc. Series A, 234, 205-230.

CraIG, R.A., 1950: The observations and photochemistry of atmospheric ozone and their meteorological significance, Meteorol. Monogr. 1, No. 2.

Dürscif, E.U. 1956: Das atmosphärische Ozon als Indikator für Strömungen in der Stratosphäre, Ark. Met. Geophys. Biok1. A, 9, 87-119.

Epsimin, E.S., C. Osterbera, and A. Ader, 1956: A new method for the determination of theoretical distribution of ozone from a ground station, Journ. of Met, 13, 319-334.

FABkx, C. et H. Buisson, 1921: Etude de l'extrémité ultraviolette du spectre solaire, J. phys. radium, 2, 197-226. 
Götz, F. W. P., A.R. Meetham, and G. M. B. Dobson, 1934: The vertical distribution of ozone in the atmosphere, Proc. Roy. Soc. London, 145, 416-446.

Гущин, Г.П. 1957: К Вопросу об нзмерении общеюо содержания атмосферного озопа и его вертикальпого распределешия, Metorology and Hydrology, 6, 26-32.

Johnson, F.S., J. O. Purowli, R. Tousex, and K. Watanabe, 1952: Direct measurement of the vertical distribution of atmospheric ozone to 70 kilometer altitude, Journ. Gesphys. Res. 57, 157-176.

REgENer, E. and V.H. 1934: Aufnahmen des ultravioletten Sonnenspektrums in der Stratosphäre und die vertikale Ozonverteilung, Phys. Z. 35, 788-793.

Sekilara, K., 1950 : Geoyhys. Mag. 22, p. 21. Pap. Met. Geophys. Met. Res. Inst. 2, (1951) 158. ibid., 3, (1952) 94' ibia., 183, ibia., 217, ibid. 4, (1953) p. 97, ibid., 6, (1955) p. 150 .

Technical Report No. 1, Institute for Solar Terrestrial Research, High Altitude Observatory of the University of Colorado, 1956: Possible response of terrestrial atmospheric circulation to changes in solar activity.

WaLton, G.F. 1957: The relation between an umkehr curve and the vertical distribution of atmospheric ozone, Quart. Journ. of Roy. Met. Soc. 83, 173-180.

\section{天空紫外線分布の研究 VIII}

\section{一 オン゙ン層との関係とついて—}

関原 㩖, 村排潔三，嘉納宗靖

天空紫外線分有とオゾン層との関係を乘鞍岳飞於故る実测と訃算飞依り吟味した。光電子增倍管とフ イルターにより紫外線の䄪 $3,200 \AA$ 付近と $3,300 \AA$ 付近の光飞つき夫々灭頂角 $0^{\circ},+15^{\circ}(+,-$ は夫々 太陽鉛值面内の太陽方向及びその反対方向の意）の方向の天空光の強度の時間的変化を测定した。そ場 合, 天頂件 $15^{\circ}$ の方向の天媔飞対する相対值の波長飞よる差が, 太陽高度 $2 \sim 3^{\circ}$ 程度飞於て急激飞增加 する事が認められた。

以上の特徴飞関し，平面大気中飞於ける 1 次散乱光の計算を吸收層を含む場合と含まない場合とにつ き行い玲味した。その絬果, 明らか飞これが上層飞於ける吸収層の影響である事がたしかめられた。これ により，地上からの测定で，反枟効果以外飞オン゙ン層の観測を行う新方法が可能である事が示唆された。 